\title{
Polycyclic aromatic hydrocarbons in the cestode Oncomegas wageneri parasite of Mexican flounder Cyclopsetta chittendeni
}

\author{
Lilia C. Soler-Jiménez ${ }^{1}$ • Emanuel Hernández-Núñez ${ }^{1}$ - Iván Velázquez-Abunader ${ }^{1}$ - Arturo Centeno-Chalé ${ }^{1}$. \\ Víctor M. Vidal-Martínez ${ }^{1}$ (D)
}

Received: 30 April 2019 / Accepted: 29 December 2019 / Published online: 1 February 2020

(C) The Author(s) 2020

\begin{abstract}
The concentrations of polycyclic aromatic hydrocarbon metabolites (PAHm) and their bioconcentration factors (BCF) were determined in the larval stages of the cestode Oncomegas wageneri, recovered from the intestine of the Mexican flounder Cyclopsetta chittendeni, in the southern Gulf of Mexico. The PAHm concentrations in $O$. wageneri were measured using fixed-wavelength fluorescence spectrometry and compared with PAHm concentrations in host bile. Oncomegas wageneri PAHm concentrations were markedly higher than those in host tissues. The highest BCF values were obtained for 1hydroxypyrene (OHP) and benzo(a)pyrene (BaP). Using a General Linear Model, a significant negative relationship was found between $O$. wageneri PAHm concentrations (as response variable) and the number of $O$. wageneri and oil well proximity. Low BCF values and PAHm concentrations in $C$. chittendeni correlated positively with $O$. wageneri PAHm concentrations. In contrast, high BCF values for PAHm concentrations in $C$. chittendeni had a negative association with $O$. wageneri PAHm concentrations. This study provides the first evidence of the presence of PAHm in intestinal larval cestodes of marine flatfishes, demonstrating levels of PAHm that were higher than levels in their hosts.
\end{abstract}

Keywords Contamination $\cdot$ Parasite $\cdot$ Oncomegas wageneri $\cdot$ Flatfish $\cdot$ Bioaccumulation $\cdot$ Bioindicator

\section{Introduction}

Marine fish can acquire polycyclic aromatic hydrocarbons (PAHs) from exposure to oil extraction sediments or oil spills (Pérez-del-Olmo et al. 2007; Pérez-del-Olmo et al. 2009; Centeno-Chalé et al. 2015). Other PAH sources are continental, such as products of the incomplete combustion of wood, coat, or even from barbecued meat (Baek et al. 1991;

Section Editor: Guillermo Salgado-Maldonado

Electronic supplementary material The online version of this article (https://doi.org/10.1007/s00436-019-06597-z) contains supplementary material, which is available to authorized users.

Víctor M. Vidal-Martínez

vvidal@ cinvestav.mx

1 Laboratorios de Parasitología y Pesquerías, Centro de Investigación y de Estudios Avanzados del IPN (CINVESTAV-IPN) Unidad Mérida, Carretera Antigua a Progreso Km. 6, Cordemex, C.P. 97310 Mérida, Yucatán, Mexico
Motorykin et al. 2015). These PAHs with terrestrial origin are transported by rivers or air to the sea (Baek et al. 1991; Morrison and Boyd 1998). In the southern Gulf of Mexico, coastal and offshore petroleum extraction is a significant economic activity (García-Cuellar et al. 2004; Vidal-Martínez et al. 2019) that, together with natural hydrocarbon release from oil seeps, exposes marine organisms to hydrocarbons. Additionally, processed hydrocarbons, such as motor oils, diesel, and lubricants, together with other contaminants, such as heavy metals, pesticides, and fertilizers (e.g., $\mathrm{N}$ and $\mathrm{P}$ in different compounds), are also transported from the continent and released in marine waters (Morrison and Boyd 1998). Consequently, benthic organisms (such as flatfishes and their parasites) are likely to be exposed to a wide variety of both inorganic and organic pollutants, including PAHs. However, research on the accumulation of organic compounds in hostparasite systems is scant (e.g., Heinonen et al. 1999, 2000; Persson et al. 2007; Brázová et al. 2012a; Oluoch-Otiego et al. 2016), especially about hydrocarbons, compared with studies on parasite-metal interactions (Tenora et al. 2000; 
Pascual and Abollo 2003; Sures et al. 2006; Barus et al. 2007; Johnson-Restrepo et al. 2008; Palm 2011; Brázová et al. 2012b; Lim and Shin 2013; Zahra et al. 2013; Brázová et al. 2015; Kleinertz et al. 2016). Difficulty in accessing crude oil for experimental tests limits studies to the occurrence of accidental oil spills (e.g., Pérez-del-Olmo et al. 2007; Pérez-delOlmo et al. 2009; Centeno-Chalé et al. 2015), compounding the lack of understanding regarding the bioaccumulation of hydrocarbons in host-parasite systems. The literature suggests a fractionation of organic compounds between parasites and their hosts related to the commonly observed bioaccumulation pattern of organic chemicals, i.e., lipophilic (represented by the octanol-water partition coefficient, $\mathrm{K}_{\mathrm{ow}}$ ) substances that are stored in lipids (Sures 2004). Generally, parasites have lower lipid contents than their hosts. Thus, the accumulation level of lipophilic substances is expected to be lower in parasites than in the host tissues (Heinonen et al. 1999, 2000). Despite this general trend, chemical fractionation in hostparasite systems can vary depending on the physiological and behavioral processes of the parasites.

When exposed, marine fish and other aquatic vertebrates have the capacity to metabolize PAH and produce excretion metabolites that are detectable in the bile (Lin et al. 1996; Aas and Klungsøyrb 1998; Aas et al. 2000; Beyer et al. 2010). Invertebrates, such as polychaetes, can also metabolize PAH and produce excretion metabolites (Tairova et al. 2009). In addition to the other techniques, the preliminary detection of these metabolites can be performed by simple and affordable techniques, such as fixed-wavelength fluorescence spectrometry (Beyer et al. 2010). As suggested by Beyer et al. (2010), even when this technique cannot distinguish between closely related PAH isomers, it can distinguish fish bile metabolites from PAH contaminated and uncontaminated sites.

Parasites can also produce metabolites as a reaction to organic compounds. For example, when larval cestodes, such as Schistocephalus solidus (a fish parasite), Echinococcus granulosus, and Taenia solium (human parasites), are exposed to organic compounds, such as 1,2-dichloro-4-nitrobenzene or 1,2-epoxy-3-(p-nitrophenoxy) propane, they produce specific metabolites through the glutathione transferase (GST) system (Torres-Rivera and Landa 2008 and references therein). Furthermore E. granulosus and T. solium are also able to use detoxification enzymes, such as thioredoxin, glutathione peroxidase, or thioredoxin glutathione reductase against organic compounds (Tsai et al. 2013; Wang et al. 2018). Here, we examine the levels of PAH metabolites in larval cestodes relative to their marine flatfish hosts using fixed-wavelength fluorescence spectrometry.

Oncomegas wageneri is a larval cestode infecting flatfishes collected from oil extraction zones of the Mexican Gulf of Mexico (Vidal-Martínez et al. 2014; Centeno-Chalé et al. 2015; Vidal-Martínez et al. 2015; Martínez-Aquino et al. 2019). This parasite is a good candidate for the detection of
PAH metabolites because it has a wide geographical distribution in the Gulf of Mexico, has a high prevalence and mean abundance in its host, and inhabits the intestine of the flatfishes where it can be exposed to whatever the host is ingesting (including food contaminated with PAH) (VidalMartínez et al. 2014). Support for this suggestion comes from the findings of Oluoch-Otiego et al. (2016), who have shown that intestinal cestodes bioaccumulate higher levels of polychlorinated biphenyls (PCBs) than their hosts. Additionally, $O$. wageneri is relatively easy to collect and identify from fish dissections.

Therefore, this parasite-host system is considered to be a potential good model for determining whether $O$. wageneri could accumulate higher concentrations of polycyclic aromatic hydrocarbon metabolites (PAHm) compared with its host, the Mexican flounder Cyclopsetta chittendeni. In this study, fixedwavelength fluorescence spectrometry was used for the following two reasons: (1) this technique is widely used around the world to detect production of PAHm in fish bile samples (Beyer et al. 2010; Pampanin et al. 2016) and (2) fixed-wavelength fluorescence spectrometry is a rapid and cost-effective technique, which is ideal to the exploratory nature of this study in trying to determine whether the larval cestodes could accumulate higher concentrations of polycyclic aromatic hydrocarbon metabolites (PAHm) than their hosts. Therefore, the aim of the present study was to determine and compare the concentrations of PAHm in intestinal larval stages of $O$. wageneri with those of their host the Mexican flounder, $C$. chittendeni, using fixedwavelength fluorescence spectrometry.

\section{Materials and methods}

\section{Collection and examination of fish}

The study area included 34 sampling stations in the southern Gulf of Mexico (Fig. 1). Samples were obtained from August to October 2015 at depths of between 10 and $175 \mathrm{~m}$, using shrimp trawl nets. The trawls lasted 50-60 min at 0.6-0.7 knots around each station. Samples were obtained from the oceanographic vessel (OV) Justo Sierra. A total of 55 Mexican flounders, $C$. chittendeni, were collected, deep frozen $\left(-20{ }^{\circ} \mathrm{C}\right)$ in individual plastic bags, and transported to CINVESTAV-IPN Mérida Unit for parasitological examination. The total length $(\mathrm{cm})$ and weight $(\mathrm{g})$ were recorded for each fish. Subsequently, the body surface, cavities, and all internal organs of each fish were examined for metazoan parasites using a dissection microscope. All the parasites found of different taxa were counted in situ and divided into two groups. The first group, which included all the parasites (i.e., digeneans, nematodes, and acanthocephalans) except O. wageneri, was preserved in $70 \%$ alcohol and used for both molecular and morphological taxonomy (see Vidal-Martínez 
Fig. 1 Sampling stations and oil wells within the Campeche Sound, southern Gulf of Mexico

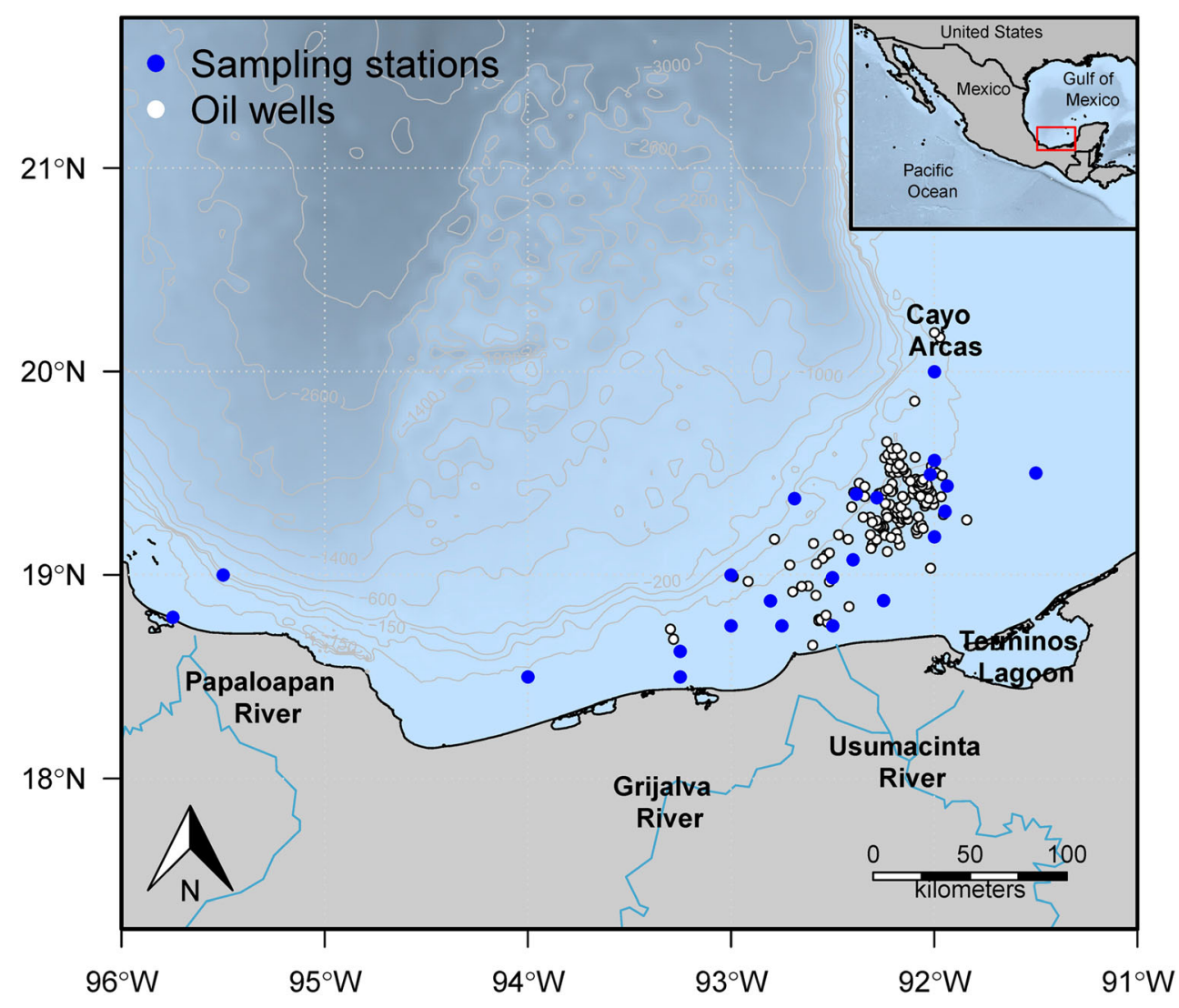

et al. (2014) for details). In contrast, the second group, which included the $O$. wageneri larvae, was frozen at $-20{ }^{\circ} \mathrm{C}$ immediately after extraction from the fish without any solution. Therefore, the larvae of $O$. wageneri used for the PAH analysis were never in contact with $70 \%$ alcohol. At the analysis time, the larvae of $O$. wageneri were washed in ultrapure water and placed directly in $1 \mathrm{~mL}$ of $1: 1(\mathrm{v} / \mathrm{v})$ solution of methanol (spectrophotometric grade) and molecular-grade water (working solution), for the determination of PAHs.

\section{Analytical procedures}

All $O$. wageneri individuals were washed in ultrapure water and analyzed for the presence of PAHm. Fixed-wavelength fluorescence spectrometry was used to measure PAHm rather than individual compounds (Beyer et al. 2010). Four PAHm families were analyzed, each having a different number of benzene rings: benzo(a)pyrene $(\mathrm{BaP})$ for hydrocarbon with five benzene rings; 1-hydroxypyrene (OHP) for hydrocarbon with four rings; phenanthrene (Phe) for hydrocarbons with three rings; and 2-naphthol (Naph) for hydrocarbon with two rings. All measurements were performed with a Thermo Scientific Lumina Fluorescence spectrofluorometer and 1$\mathrm{cm}$ quartz cells. Spectral data acquisition and processing were carried out with the use of Luminous V.3.0 software.

For the extraction of PAHm, $0.01 \mathrm{~g}$ of $O$. wageneri individuals was homogenized using a manual tissue homogenizer
(TissueRuptor Qiagen) in $1 \mathrm{~mL}$ of a 1:1 (v/v) solution of methanol (spectrophotometric grade) and molecular-grade water (working solution). The homogenized samples were centrifuged at $4700 \mathrm{~g}$ for $10 \mathrm{~min}$ (Centrifuge Thermo Scientific Micro CL 17) to separate the solid and liquid phases. Subsequently, $25 \mu \mathrm{L}$ aliquots of liquid phase (containing organics compounds) were placed in 1-cm quartz cells with $2 \mathrm{~mL}$ of working solution for spectrofluorometric measurement. The procedure was applied also to bile samples from Mexican flounders. Four calibration curves, with six points each, were built using the following four standard solutions: $0.63-3.11 \mathrm{ng} \mathrm{mL}^{-1}$ for benzo[a]pyrene, $0.55-$ $2.71 \mathrm{ng} \mathrm{mL}^{-1}$ for 1-hydroxypyrene, $44.38-219.75 \mathrm{ng} \mathrm{mL}^{-1}$ for phenanthrene, and 35.95-177.78 $\mathrm{ng} \mathrm{mL}^{-1}$ for 2-naphtol (Supplementary Material, Fig. S1). The calibration curves with their corresponding correlation coefficient $(R)$ and determination coefficient $\left(R^{2}\right)$ were calculated by least-square linear regression analysis. The limits of detection and quantification were calculated from the calibration curves, using the following equations: $\mathrm{LOD}=3.3_{\mathrm{S} 0}$ and $\mathrm{LOQ}=10_{\mathrm{S} 0}(\mathrm{ICH}$ 2005), where LOD corresponds to the limit of detection; LOQ, the limit of quantification; and S0, the standard deviation of the blank (Bruce 1999). The standard curves were used to estimate the approximate concentration of PAHm in unknown samples. Table 1 shows the coefficients of correlation $(R)$ and determination $\left(R^{2}\right)$, confirming the linearity of the method with values of $R>0.99$ for all PAHs determining the 
region of the curve where there is a direct relation between the instrumental response and the concentration of the analyte. The specific wavelength conditions for each compound required the calibration curves to be created separately; samples were analyzed at each of the wavelength conditions. An analysis of variance refuted the null hypothesis of equal variances, so the homogeneity of variances was assessed with ANOVA regression test, because it is not sensitive to the violation of this assumption (Supplementary Material, Tables S1 to S4).

In the Supplementary Material (Tables S5 to S8), levels 1, 2 , and 3 represent the percentage of recovery and the relative standard deviation, the values of which meet the acceptance criteria of $100 \% \pm 25 \%$ and relative standard deviation variation between 0.7 to $15 \%$ for fourth-group PAHs (EURACHEM/CITAC 2003).

\section{Data analysis}

Bioconcentration factors (BCFs) for PAHm were determined, based on Sures et al. (1999), where the ratio of PAHm concentration in the parasite relative to that in host bile $(\mathrm{BCF}=$ $\mathrm{C}_{\text {(parasite) }} / \mathrm{C}_{\text {(host bile) }}$ ) was calculated. In addition, differences between total PAHm concentrations ( $\mathrm{PAHm})$ and those of individual PAHm in parasites and in fish bile were tested for statistical significance using the KruskalWallis non-parametric analysis with multiple comparisons of mean ranks for all samples and Dunn's test for post-hoc multiple comparisons (Zar 1999). The significance of all statistical analyses was established at $\alpha=0.05$ unless otherwise stated. SigmaPlot 11 software was used for the statistical analyses.

Additionally, the geostatistical kriging method (Cressie 1993) was used to determine the existence of spatial patterns of total PAHm concentration in parasites and hosts. This method calculates the average weights based on the observed values, as well as their spatial trends through variogram functions (Bellier et al. 2007). Four models were tested (spherical, cubic, Gaussian, and Matern) to determine which variogram best described the spatial pattern of PAHm concentrations. PAHm values were transformed to $\log$ (PAHm). The best model was selected with the Akaike information criterion (AIC), as proposed by Burnham and Anderson (2002). The geostatistical analyses were conducted using the geoR package (Ribeiro and Diggle 2016) with R programming language (R Core Team 2017).

Exploratory data analysis was carried out to evaluate parasite PAHm concentration behavior with respect to six independent variables (number of individual parasites, fish total weight, individual parasite weight, PAHm concentration in host, BCF, and proximity to oil extraction wells). For this analysis, a Pearson's correlation matrix was used to test for collinearity. A value of $R \geq 0.7$ was established as a decision criterion for discarding those variables with collinearity problems (Zar 1999; Cárdenas-Palomo et al. 2015). The link function $(\eta=\mu)$ was selected considering the following two criteria: highest deviance explained and lowest AIC value (Burnham and Anderson 2002). A stepwise selection model was used to select the independent variables to be included in the final model. All procedures were performed using glm function of the base package of $R$ programming language ( $R$ Core Team 2017).

To determine the potential effect of the six independent variables on the total PAHm concentrations in parasite (the dependent or response variable), a generalized lineal model (GLM) was used (Nelder and Wedderburn 1972). These models have the flexibility of adding quadratic or higherorder effects to improve the explanation of the response variable.

Because there is no background about the possible distribution that could be followed by the total PAHm concentration in parasites, three probability distributions were tested (Gaussian, gamma, and inverse Gaussian). As a result of the previous analysis, the Gaussian distribution was chosen because the error of the fitted model was getting closer to $\varepsilon \sim N$ $\left(0, \sigma^{2}\right)($ Zar 1999).

\section{Results}

A total of 55 O. wageneri pools obtained from 55 C. chittendeni from 34 sampling stations were used for comparison of PAHm concentrations. The mean PAHm concentrations for $O$. wageneri $(\bar{x}=2139.33 \pm 2664.20 \mu \mathrm{g} / \mathrm{g})$ were found to be significantly higher than those of their hosts $(\bar{x}=$ $12.91 \pm 32.10 \mu \mathrm{g} / \mathrm{g})(P<0.05)$. Significant differences

Table 1 Parameters for equations of each calibration curve

\begin{tabular}{lllllllllll}
\hline Compounds & Excitation (nm) & Emission (nm) & Rings & Range (ng/mL) & LOD $(\mathrm{ng} / \mathrm{mL})$ & LOQ $(\mathrm{ng} / \mathrm{mL})$ & $A$ & $\beta$ & $R$ & $R^{2}$ \\
\hline Benzo(a)pyrene & 364 & 404 & 5 & $0.63-3.11$ & 0.003 & 0.008 & 34.90 & 3971.00 & 0.99 & 0.99 \\
1-Hydroxypyrene & 348 & 386 & 4 & $0.55-2.71$ & 0.001 & 0.003 & 612.95 & 7654.50 & 0.99 & 0.99 \\
Phenanthrene & 363 & 392 & 3 & $44.38-219.75$ & 0.943 & 2.859 & 67.02 & 88.01 & 0.99 & 0.99 \\
2-Naphthol & 308 & 470 & 2 & $35.95-177.78$ & 1.738 & 5.267 & 427.95 & 47.23 & 0.99 & 0.98 \\
\hline
\end{tabular}

$\mathrm{nm}$, nanometers; LOD, limit of detection; LOQ, limit of quantification; $A$, intercept value; $\beta$, slope; $R^{2}$, coefficient of determination 
between $O$. wageneri and fish bile were confirmed for total PAHm concentrations $(H=81.8 ; P<0.05)$ and for each PAHm concentration, showing significantly higher values in parasites in all cases $(\mathrm{BaP} H=7.1, P<0.05$; $\mathrm{OHP} \mathrm{H}=8.246$, $P<0.05$; $\mathrm{Phe} \mathrm{H}=5.17, P<0.05$; and Naph $\mathrm{H}=7.1, P<0.05)$ (Fig. 2). Comparison between each PAHm concentration in $O$. wageneri and fish bile separately showed that naphthol concentration values were significantly higher $(P<0.05)$ in both parasites and hosts compared with all other PAHm measured. BaP and OHP presented the lowest values (Fig. 2). The $\mathrm{BCF}$ ratios indicated that parasites had higher PAHm concentrations than those of their host tissues. The highest BCF values were obtained for 1-hydroxypyrene (OHP) (14,597.9) and benzo(a)pyrene (BaP) (6957.5), compared with those obtained for phenanthrene (Phe) (1003.1) and 2-naphthol (Naph) (140.8).

The spatial distribution pattern for total PAHm concentration in $O$. wageneri and $C$. chittendeni in the study area is shown in Fig. 3. High total PAHm concentrations in parasites were found just off the Campeche coast and near Cayo Arcas. For the hosts, total PAHm concentrations were high on the Campeche coast.

\section{General linear model}

Of the six variables originally included in the GLM model to explain the behavior of parasite total PAHm concentrations, only four were retained. These variables were number of individual parasites, proximity to oil wells, BCF, and host total PAH concentrations (Table 2). The final model explained $60 \%$ of deviance, in most cases showing a non-linear relationship with the dependent variable (Fig. 4). With increase in the number of individual parasites, there was a concave up behavior, whereas, with proximity to oil wells, there was a linear decrease in the parasite total PAH concentration with increase in the distance from the oil wells (Fig. 4A and B). The behavior of BFC and host total PAHm concentration was also nonlinear. In both cases, the function had a concave down shape, initially presenting a positive effect on parasite total PAHm concentration, followed by an inflection point and a decrease in the dependent variable with increase in the values of the independent variables (Fig. 4C and D).

\section{Discussion}

This study provides the first evidence to our knowledge of the capacity of the larval parasite $O$. wageneri to accumulate and probably produce $\mathrm{PAH}$ metabolites, highlighting the role of this fish parasite as an indicator of bioaccumulation compared with that of their hosts. More importantly, the results showed that the larval cestode,
O. wageneri, accumulated PAHm in higher concentrations than their fish host, $C$. chittendeni.

The higher accumulation capacity of $O$. wageneri compared with $C$. chittendeni tissues was also confirmed for BCFs obtained for all four hydrocarbon metabolites. Several studies have demonstrated that some parasite groups, such as adult acanthocephalans, cestodes, and some nematodes, are able to bioaccumulate both organic and inorganic compounds in higher concentrations than their hosts (Tenora et al. 2000; Heinonen et al. 2001; Sures and Siddall 2001, 2003; Pascual and Abollo 2003; Sures 2003; Sures and Reimann 2003; Sures et al. 2006; Barus et al. 2007; Azmat et al. 2008; Jankovská et al. 2012; Brázová et al. 2012a; Brázová et al. 2012b; Amini et al. 2013; Nachev et al. 2013; Zahra et al. 2013; Brázová et al. 2015; Nachev and Sures 2016; Kleinertz et al. 2016; Oluoch-Otiego et al. 2016); even the presence of some parasitic organisms may influence positively their hosts (Brázová et al. 2012a). Brázová et al. (2012a) found that the acanthocephalan Acanthocephalus lucii attached to the intestine of perch absorbed significantly higher concentrations of polychlorinated biphenyls (PCBs) than the muscles, liver, kidney, brain, and adipose tissue of their host. In infected perch, PCB levels in the liver and muscle were about 20 times lower and 3 times lower, respectively.

The higher concentration of PAHm in parasites with respect to their host has at least the following four possible explanations: (1) O. wageneri absorb PAHm from the host and do not excrete them as efficiently as their host; (2) high numbers of $O$. wageneri individuals interfere with absorption of the compounds by the host, affecting PAHm concentrations in both parasite and host; (3) that the PAHm bioconcentration in $O$. wageneri depends on the partition coefficient $\left(\mathrm{K}_{\mathrm{ow}}\right)$ of each hydrocarbons, because higher BCFs were found for PAH with higher number of rings; (4) $O$. wageneri individuals produce PAHm metabolites in higher concentrations than their hosts. In our view, based on the available information, the most probable explanations are (1), (2), and (3). However,

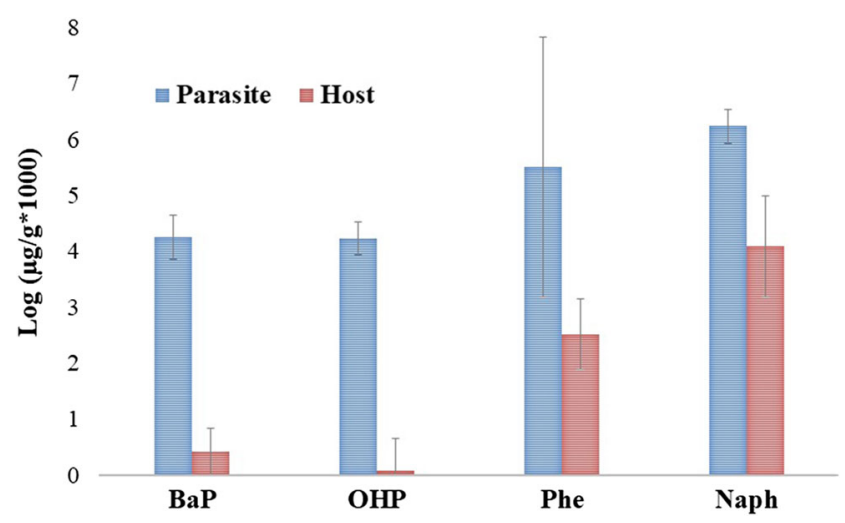

Fig. 2 PAHm concentrations in Oncomegas wageneri and Cyclopsetta chittendeni bile. BaP, benzo(a)pyrene; OHP, 1-hydroxypyrene; Phe, phenanthrene; Naph, 2-naphthol 
explanation (4) cannot be discarded. Even though it is likely that $O$. wageneri acquires PAH metabolites from C. chittendeni, the possibility that the parasite produces its own PAH metabolites cannot be ruled out. Clearly, to determine whether or not $O$. wageneri produces its own PAH metabolites requires further research.

The first explanation for the higher concentration of PAHm in parasites with respect to their host is that $O$. wageneri individuals absorb PAHm from the host but do not excrete them efficiently. Owing to the lack of a digestive system, the substances enter the cestodes across the tegument; therefore, the cestodes ingest and absorb the same type of food acquired by the host (Nachev et al. 2017; Sures et al. 2017), a characteristic that places $O$. wageneri in the same trophic level of the host. For such host-parasite systems, no significant difference between pollutant concentrations in the hosts and the parasites would be expected (see Le et al. 2014). However, our results showed a higher concentration of PAHm in $O$. wageneri with respect to the Mexican flounder. Therefore, the most likely explanation is that $O$. wageneri does not eliminate these PAHm as efficiently as the fish and accumulates these compounds. For vertebrates, such as fish, once the PAH are in the body, they are metabolized by the enzymes of the superfamily of cytochrome P450 (CYP) to more water-soluble hydroxyPAH (OH-PAH) (Motorykin et al. 2015). For many years, it was suggested that oxidative metabolism was not a significant process in parasitic helminths, and cytochrome P450 (CYP) activity was generally absent or occurred at a very low level (Pemberton and Barrett 1989; Precious and Barrett 1989; Barrett 1998, 2009; Torres-Rivera and Landa 2008; Yadav et al. 2010). However, it has been shown that larval cestodes, such as S. solidus (a fish parasite), E. granulosus, and T. solium, (human parasites) are able to produce specific metabolites through the glutathione transferase (GST) system in response to the exposure to organic compounds, such as 1,2dichloro-4-nitrobenzene or 1,2-epoxy-3-(p-nitrophenoxy) propane (Torres-Rivera and Landa 2008 and references therein). Furthermore, E. granulosus and T. solium are also able to use detoxification enzymes, such as thioredoxin, glutathione peroxidase, or thioredoxin glutathione reductase, against organic compounds (Tsai et al. 2013; Wang et al. 2018). Additionally, CYP oxidase presence has been demonstrated in some parasitic nematodes (Kotze 1997; Cvilink et al. 2008; Laing et al. 2015). For example, the genome of Caenorhabditis elegans encodes 80 CYPs (Menzel et al. 2001, 2005). Cvilink et al. (2008) showed that CYP activity is higher in the larval stages than in adult stages of Haemonchus contortus, which reflects an increased metabolic activity in response to exposure of free-living stages to environmental toxins. All this bring us to suggest that $O$. wagener would be eliminating PAHm but not as efficiently as their host, finally acting as a sinkhole of PAHm. Similar arguments
Fig. 3 Spatial distribution patterns of total PAHm concentrations in Oncomegas wageneri (parasites) and Cyclopsetta chittendeni (host). Red areas on maps represent a high mean PAHm concentration for the organisms sampled at each station, whereas blue zones represent a low mean PAHm concentration

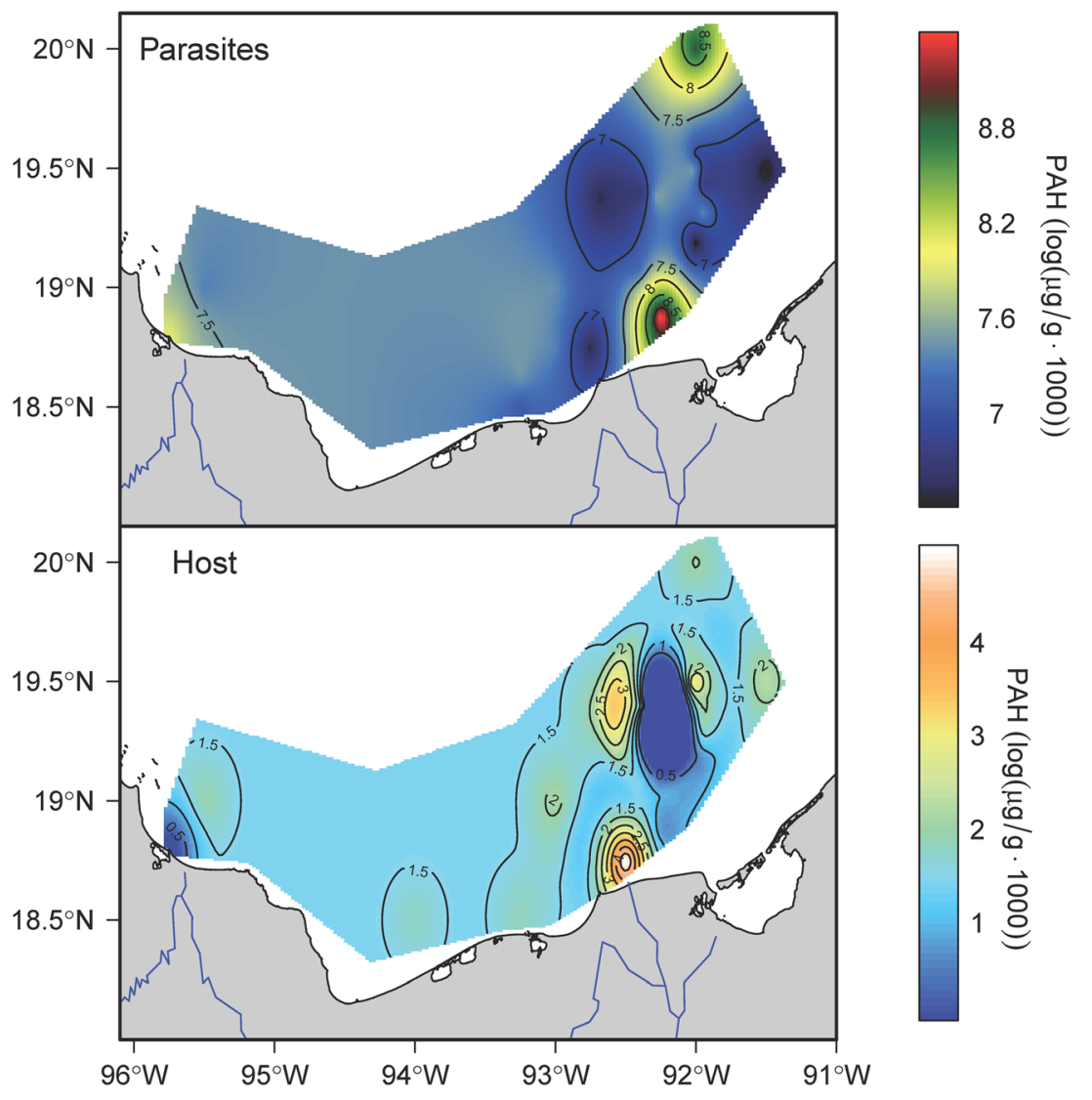


Table 2 Coefficients of the best general linear model (GLM), with parasite PAHm concentration as dependent variable and four independent variables. The asterisk indicates statistical significance of the coefficient
$(P<0.05)$. Values of the Akaike information criterion (AIC) of the distributions tested for the Generalized Lineal Model (GLM) are shown in Table S9

\begin{tabular}{|c|c|c|c|c|}
\hline Variable & Coefficient & Standard error of coefficient & $t$ value & $P$ value \\
\hline Intercept & $5.193 \mathrm{e}+06$ & $1.015 \mathrm{e}+06$ & 5.118 & $5.650 \mathrm{e}^{-}-06^{*}$ \\
\hline Number of parasites & $\begin{array}{c}-1.486 \mathrm{e}+ \\
05\end{array}$ & $2.628 \mathrm{e}+04$ & -5.655 & $8.930 \mathrm{e}-07 *$ \\
\hline $\mathrm{BCF}$ & $2.422 \mathrm{e}+03$ & $3.312 \mathrm{e}+02$ & 7.313 & $2.740 \mathrm{e}-09^{*}$ \\
\hline Proximity to oil well & $\begin{array}{c}-1.231 \mathrm{e}+ \\
04\end{array}$ & $5.106 \mathrm{e}+03$ & -2.410 & $0.0199 *$ \\
\hline PAHm in host & $1.375 \mathrm{e}+02$ & $6.065 \mathrm{e}+01$ & 2.267 & $0.0281 *$ \\
\hline
\end{tabular}

for parasites acting as sinkholes of heavy metals have been provided by Nachev et al. (2017) and Sures et al. (2017).

Our second explanation was that high numbers of $O$. wageneri individuals could be interfering with the absorption of compounds by the host, which in turn would be affecting PAHm concentrations in both parasites and host. Apparently, this is the case since our results revealed significant negative associations between PAHm concentrations in parasites and the intensity of infection. A biodilution effect can explain this pattern. The biodilution theory has been confirmed through laboratory experiments and synoptic studies of multiple ecosystems, where the biological accumulation of several compounds depends on the biomass found (Chen and Folt 2005). For example, Brázová et al. (2015) recorded that a high intensity of infection was consistently associated with low heavy metal concentration in Acanthocephalus lucii and Proteocephalus percae. Likewise, Heinonen et al. (2000) found that uninfected clams Pisidium amnicum accumulated benzo(a)pyrene (BaP) and 2,4,5-trichlorophenol at significantly higher levels than clams infected with trematodes. Indeed, our results concur with the general trend reported by other authors with respect to the decrease in pollutant concentration in the hosts with increase in the number of parasites (Sures and Siddall 2003).

Our third explanation was that the PAHm bioconcentration in $O$. wageneri depended of the partition coefficient, because higher BCFs were found for $\mathrm{PAH}$ with higher number of rings. First, the PAHm concentrations in parasites were at least four orders of magnitude higher than those in the hosts. Second, the ranking order of BCFs $(\mathrm{OHP}>\mathrm{BaP}>\mathrm{Phe}>$ Naph) suggests that the high molecular weight PAH, namely OHP and BaP, even when they had the lowest concentrations in both parasites and hosts (Fig. 2) were retained at higher proportions in parasites than in their hosts. This result suggested that the parasites were unable to eliminate these high molecular weight PAHm compared with the fish hosts, which
Fig. 4 Fit plots for general linear models (GLM) that show the effect of the four independent variables retained by the GLM model on the total parasite PAHm concentration as the dependent variable
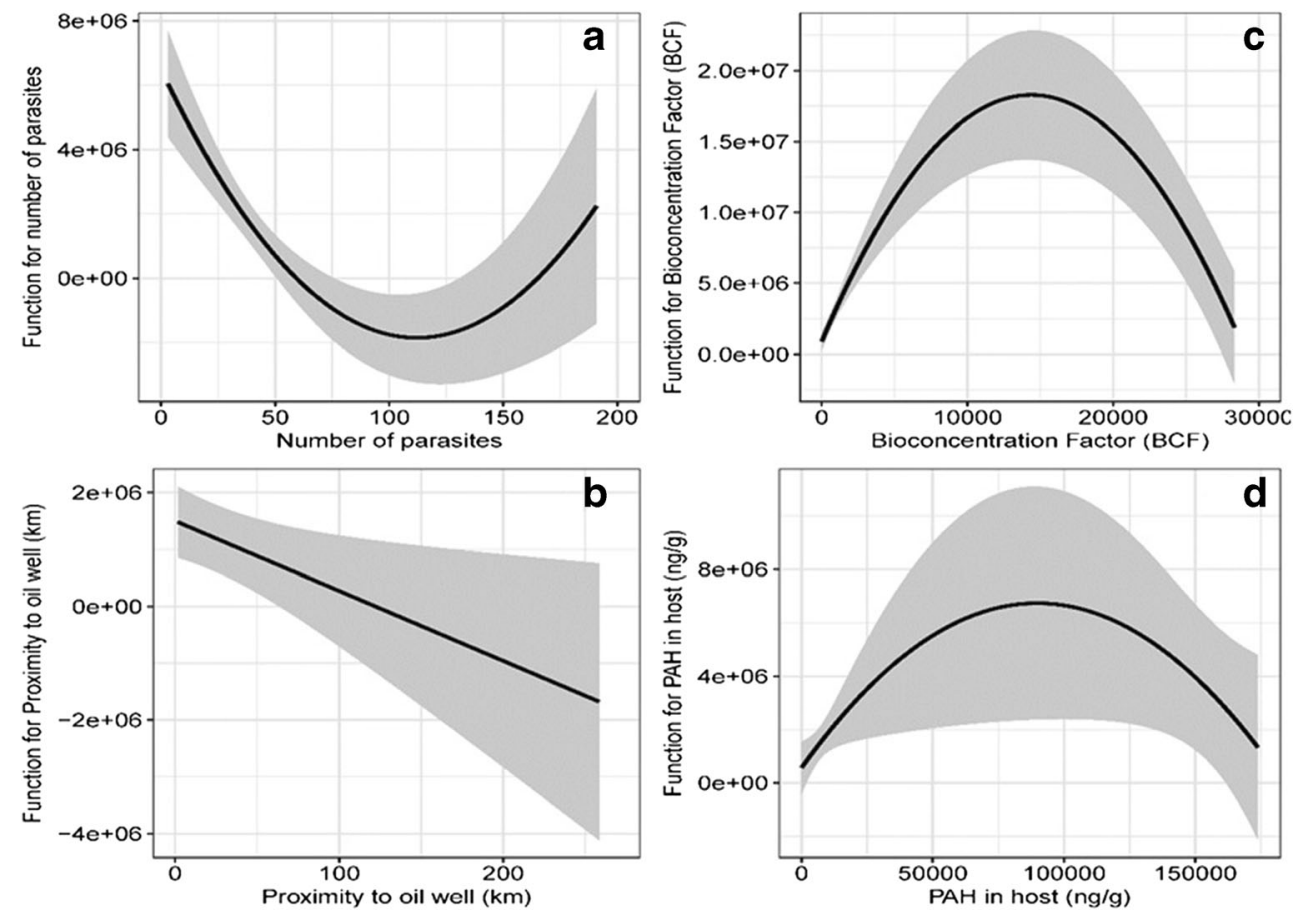
contained very low levels of these hydrocarbons. A possible reason is that aromatic compounds of high molecular weight are more resistant to the mechanisms of degradation owing to the number of benzene rings that they have (4-5), in addition to the energy required to break these bonds (Abdel-Shafy and Mansour 2016). In this case, O. wageneri apparently would not be able to remove or excrete this type of high molecular weight PAHm. In contrast, the BCFs for Naph and Phe were lower than those for OHP and $\mathrm{BaP}$, which indicates that both parasites and hosts are able to remove these low molecular weight PAHm, but certainly at a greater extent in the host than in the parasite (Fig. 2). This pattern is also reflected in the results of the GLM analysis (Fig. 4). Under these conditions, we infer a possible PAHm removal process by $O$. wageneri which is related to the chemical structure and molecular weight of each compound. Therefore, the bioaccumulation not only involves bioavailability and absorption potential, but it is also strongly influenced by chemical compoundspecific properties, such as lipophilicity (represented by the octanol-water partition coefficient, $\mathrm{K}_{\mathrm{ow}}$ ), which is closely related to molecular weight of each compound and the individual lipid concentration (Le et al. 2014). In general, the relation between the hydrocarbon concentrations in the parasite $O$. wageneri and in the fish $C$. chittendeni increased with increasing $\mathrm{K}_{\mathrm{ow}}$ and the number of rings. Previous studies have shown that lipid concentrations in the parasites (primarily intestinal endoparasites) are usually lower than the corresponding concentrations in their hosts (Le et al. 2014). Therefore, because they have lower overall lipid contents, the accumulation of lipophilic substances is expected to be lower in parasites than in the host tissues. However, our study found the opposite pattern - higher lipophilic concentrations in parasite tissues. This is likely a result of the fact that (1) lipid concentrations found in $O$. wageneri apparently were enough to accumulate PAHm, at least in concentrations higher than its host C. chittendeni or (2) the partition behavior of PAHm in this parasite-host system was different than for other organic pollutants (e.g., polychlorinated biphenyls) (Heinonen et al. 1999; Persson et al. 2007; Le et al. 2014). Interestingly, Heinonen et al. (2001) found an increased survival and lethal body burden of infected compared with uninfected bivalves exposed to pentachlorophenol (PCP). They suggested that these differences may be associated with the higher lipid content found in parasites which could change the internal distribution of PCP. Additionally, Yang et al. (2009) explain that cestodes cannot synthesize long-chain fatty acids and they efficiently obtain lipids directly from their host's intestinal lumen. Thus, cestodes probably absorb PAHm with the contents of the host intestinal lumen. Certainly, more intensive laboratory work is necessary to define the behavior of chemical fractionation of PAHm in host-parasite systems.

Our results also showed a spatial trend of increasing parasite number and decreasing parasite PAHm concentration with increase in the distance from the oil wells. Several studies have reported that, in general, concentrations of hydrocarbons, barium, and trace metals decrease with increasing distance from the drill sites, with positive effect for benthic communities. For example, Ellis et al. (2012) documented the change in benthic communities, including loss of biodiversity and a stop in feeding behavior owing to the proximity to oil exploration and extraction activities. Because PAHm in $O$. wageneri were higher than those in their hosts, our results suggest that this type of biomarker would provide more precise information on the exposure of both parasites and their host to pollutants than effect indicators, such as changes in metrics at population or community levels, because the latter are influenced by other environmental conditions over time.

\section{Conclusions}

This study showed that the larval cestode, $O$. wageneri, was able to accumulate PAHm in higher concentrations than its host, the Mexican flounder C. chittendeni. Apparently, the reason for this difference was that the fish has greater capacity to eliminate PAHm than the parasite. Under these circumstances, this parasite-host system $O$. wageneri could be considered as a better indicator of PAHm bioavailable concentrations in oil extraction zones than its fish host. Based on the results presented here, it is unclear whether $O$. wageneri is able to produce its own PAHm metabolites or if it simply acquires them from its host. Certainly, laboratory experiments are required to address this issue.

Acknowledgments The authors thank Ivan Chan-Cua, Clara VivasRodríguez, Gregory Arjona-Torres, Nadia Herrera Castillo, Francisco Puc-Itza, and Mirella Hernández de Santillana for support with the field and laboratory work.

Funding This work was supported by CONACYT and the Secretariat of Energy, through the Sector Fund CONACYT-Secretariat of EnergyHydrocarbons, project 201441. This is a contribution of the Gulf of Mexico Research Consortium (CIGoM).

Data availability The datasets generated during and/or analyzed during the current study are available from the corresponding author upon reasonable request.

\section{Compliance with ethical standards}

Conflict of interest The authors declare that they have no conflict of interest.

Ethical approval All procedures performed in studies involving animals were in accordance with the ethical standards of the institution.

Open Access This article is licensed under a Creative Commons Attribution 4.0 International License, which permits use, sharing, 
adaptation, distribution and reproduction in any medium or format, as long as you give appropriate credit to the original author(s) and the source, provide a link to the Creative Commons licence, and indicate if changes were made. The images or other third party material in this article are included in the article's Creative Commons licence, unless indicated otherwise in a credit line to the material. If material is not included in the article's Creative Commons licence and your intended use is not permitted by statutory regulation or exceeds the permitted use, you will need to obtain permission directly from the copyright holder. To view a copy of this licence, visit http://creativecommons.org/licenses/by/4.0/.

\section{References}

Aas E, Klungsøyrb J (1998) PAH metabolites in bile and EROD activity in North Sea fish. Mar Environ Res 46:229-232. https://doi.org/10. 1016/S0141-1136(97)00035-4

Aas E, Baussant T, Balk L, Liewenborg B, Andersen OK (2000) PAH metabolites in bile, cytochrome P4501A and DNA adducts as environmental risk parameters for chronic oil exposure: a laboratory experiment with Atlantic cod. Aquat Toxicol 51(2):241-258. https://doi.org/10.1016/S0166-445X(00)00108-9

Abdel-Shafy HI, Mansour MS (2016) A review on polycyclic aromatic hydrocarbons: source, environmental impact, effect on human health and remediation. Egyp J Pet 25(1):107-123. https://doi.org/ 10.1016/j.ejpe.2015.03.011

Amini Z, Pazooki J, Abtahi B, Shokri MR (2013) Bioaccumulation of Zn and $\mathrm{Cu}$ in Chasar bathybius (Gobiidae) tissue and its nematode parasite Dichelyne minutus, southeast of the Caspian Sea, Iran. Indian J Mar Sci 42:196-200

Azmat R, Fayyaz S, Kazi N, Mahmood SJ, Uddin F (2008) Natural bioremediation of heavy metals through nematode parasite of fish. Biotechnology 7:139-143. https://doi.org/10.3923/biotech.2008. 139.143

Baek SO, Field RA, Goldstone ME, Kirk PW, Lester JN, Perry R (1991) A review of atmospheric polycyclic aromatic hydrocarbons: sources, fate and behavior. Water Air Soil Pollut 60(3-4):279-300

Barus V, Jrkovsky J, Prokes M (2007) Philometra Ovata (Nematoda: Philometroidea): a potential sentinel species of heavy metal accumulation. Parasitol Res 100:929-933. https://doi.org/10.1007/ s00436-006-0384-8

Barrett J (1998) Cytochrome P450 in parasitic protozoa and helminths. Comp Biochem Physiol, C: Toxicol Pharmacol 121:181-183. https://doi.org/10.1016/S0742-8413(98)100397

Barrett J (2009) Forty years of helminth biochemistry. Parasitology 136: 1633-1642. https://doi.org/10.1017/S003118200900568X

Bellier E, Monestiez P, Durbec JP, Candau JN (2007) Identifying spatial relationships at multiple scales: principal coordinates of neighbour matrices (PCNM) and geostatistical approaches. Ecography 30: 385-399. https://doi.org/10.1111/j.0906-7590.2007.04911.x

Beyer J, Jonsson G, Porte C, Krahn MM, Ariese F (2010) Analytical methods for determining metabolites of polycyclic aromatic hydrocarbon $(\mathrm{PAH})$ pollutants in fish bile: a review. Environ Toxicol Pharmacol 30:224-244. https://doi.org/10.1016/j.etap.2010.08.004

Brázová T, Hanzelová V, Miklisová D (2012a) Bioaccumulation of six PCB indicator congeners in a heavily polluted water reservoir in eastern Slovakia: tissue-specific distribution in fish and their parasites. Parasitol Res 111:779-786. https://doi.org/10.1007/s00436012-2900-3

Brázová T, Torres J, Eira C, Hanzelová V, Miklisová D, Šalamún P (2012b) Perch and its parasites as heavy metal biomonitors in a fresh water environment: the case study of the Ružín water reservoir,
Slovakia. Sensors 12:3068-3081. https://doi.org/10.3390/ s120303068

Brázová T, Hanzelová V, Miklisová D, Šalamún P, Vidal-Martínez V (2015) Host-parasite relationships as determinants of heavy metal concentrations in perch (Perca fluviatilis) and its intestinal parasite infection. Ecotoxicol Environ Saf 122:551-556. https://doi.org/10. 1016/j.ecoenv.2015.09.032

Bruce GR (1999) Estimates of precision in a standard addition analysis. J Chem Educ 76(6):805-807. https://doi.org/10.1021/ed076p805

Burnham K, Anderson DR (2002) Model selection and multimodel inference: a practical information-theoretic approach, 2nd edn. Colorado Cooperative Fish and Wildlife Research Unit Colorado State University Fort Collins, USA

Cárdenas-Palomo N, Herrera-Silveira J, Velázquez-Abunader I, Reyes O, Ordoñez U (2015) Distribution and feeding habitat characterisation of whale sharks Rhincodon typus in a protected area in the north Caribbean Sea. J Fish Biol 86(2):668-686. https://doi.org/10.1111/ jfb. 12589

Centeno-Chalé OA, Aguirre-Macedo ML, Gold-Bouchot G, VidalMartínez VM (2015) Effects of oil spill related chemical pollution on helminth parasites in Mexican flounder Cyclopsetta chittendeni from the Campeche Sound, Gulf of Mexico. Ecotoxicol Environ Saf 119:162-169. https://doi.org/10.1016/j.ecoenv.2015.04.030

Chen CY, Folt CL (2005) High plankton densities reduce mercury biomagnification. Environ Sci Technol 39:115-121. https://doi. org/10.1021/es0403007

Cressie NAC (1993) Statistics for spatial data. In: Wiley series in probability and statistics. John Wiley \& Sons, New York. https://doi.org/ 10.1002/9781119115151

Cvilink V, Skalova L, Szotakova B, Lamka J, Kostiainen R, Ketola RA (2008) LC-MS-MS identification of albendazole and flubendazole metabolites formed ex vivo by Haemonchus contortus. Anal Bioanal Chem 391:337-343. https://doi.org/10.1007/s00216-0081863-9

Ellis JI, Fraser G, Russell J (2012) Discharged drilling waste from oil and gas platforms and its effects on benthic communities. Mar Ecol Prog Ser 456:285-302. https://doi.org/10.3354/meps09622

EURACHEM/CITAC Guide (2003) Traceability in chemical measurement: a guide to achieving comparable results in chemical measurement. http://www.citac.cc/EC_Trace_2003.pdf

García-Cuellar A, Arreguín-Sánchez F, Hernández-Vázquez S, LluchCota DB (2004) Impacto ecológico de la industria petrolera en la Sonda de Campeche, México, tras tres décadas de actividad: una revisión. Interciencia 29:311-319 0378-1844/04/06/311-09

Heinonen J, Kukkonen JVK, Holopainen IJ (1999) The effects of parasites and temperature on the accumulation of xenobiotics in a freshwater clam. Ecol Appl 9:475-481. https://doi.org/10.2307/2641137

Heinonen J, Kukkonen JVK, Holopainen IJ (2000) Toxicokinetics of 2,4, 5-trichlorophenol and benzo(a)pyrene in the clam Pisidium amnicum: effects of seasonal temperatures and trematode parasites. Arch Environ Contam Toxicol 39:352-359. https://doi.org/10.1007/ s002440010115

Heinonen J, Kukkonen JVK, Holopainen IJ (2001) Temperature- and parasite-induced changes in toxicity and lethal body burdens of pentachlorophenol in the freshwater clam Pisidium amnicum. Environ Toxicol Chem 20:2778-2784. https://doi.org/10.1002/etc. 5620201217

Jankovská I, Miholová D, Lukešová D, Kalous L, Válek P, Romočuský Š, Vadlejch J, Petrtýl M, Langrová I, Čadková Z (2012) Concentrations of $\mathrm{Zn}, \mathrm{Mn}, \mathrm{Cu}$ and $\mathrm{Cd}$ in different tissues of perch (Perca fluviatilis) and in perch intestinal parasite (Acanthocephalus lucii) from the stream near Prague (Czech Republic). Environ Res 112:83-85. https://doi.org/10.1016/j.envres.2011.11.003

Johnson-Restrepo B, Olivero-Verbel J, Lu S, Guette-Fernandez J, Baldiris-Avila R, O’Byrne-Hoyos I, Aldous KM, Addink R, Kannan K (2008) Polycyclic aromatic hydrocarbons and their 
hydroxylated metabolites in fish bile and sediments from coastal waters of Colombia. Environ Pollut 151:452-459. https://doi.org/ 10.1016/j.envpol.2007.04.011

Kleinertz S, Eckhardt KU, Theisen S, Palm HW, Leinweber P (2016) Acanthocephalan fish parasites (Rhadinorhynchidae Lühe, 1912) as potential biomarkers: molecular-chemical screening by pyrolysis-field ionization mass spectrometry. J Sea Res 113:51-57. https://doi.org/10.1016/j.seares.2015.10.001

Kotze AC (1997) Cytochrome P450 monooxygenase activity in Haemonchus contortus (Nematoda). Int J Parasitol 27:33-40. https://doi.org/10.1016/S0020-7519(96)00161-0

Laing R, Bartley DJ, Morrison AA, Rezansoff A, Martinelli A, Laing ST, Gilleard JS (2015) The cytochrome P450 family in the parasitic nematode Haemonchus contortus. Int J Parasitol 45:243-251. https://doi.org/10.1016/j.ijpara.2014.12.001

Le YTT, Rijsdijk L, Sures B, Hendriks J (2014) Accumulation of persistent organic pollutants in parasites. Chemosphere 108:145-151. https://doi.org/10.1016/j.chemosphere.2014.01.036

Lim HH, Shin HS (2013) Simultaneous determination of 2-naphthol and 1-hydroxypyrene in fish and shellfish contaminated with crude oil by gas chromatography-mass spectrometry. Food Chem 138:791796. https://doi.org/10.1016/j.foodchem.2012.11.059

Lin ELC, Cormier SM, Torsella JA (1996) Fish biliary polycyclic aromatic hydrocarbon metabolites estimated by fixed-wavelength fluorescence: comparison with HPLC-fluorescent detection. Ecotoxicol Environ Saf 35(1):16-23. https://doi.org/10.1006/eesa.1996.0077

Martínez-Aquino A, Vidal-Martínez VM, Ceccarelli S, Méndez O, SolerJiménez L, Aguirre-Macedo L (2019) Phylogeny, genetics, and the partial life cycle of Oncomegas wageneri in the Gulf of Mexico. Curr Zool zoz045. https://doi.org/10.1093/cz/zoz045

Menzel R, Bogaert T, Achazi R (2001) A systematic gene expression screen of Caenorhabditis elegans cytochrome P450 genes reveals CYP35 as strongly xenobiotic inducible. Arch Biochem Biophys 395:158-168. https://doi.org/10.1006/abbi.2001.2568

Menzel R, Rodel M, Kulas J, Steinberg CE (2005) CYP35: xenobiotically induced gene expression in the nematode Caenorhabditis elegans. Arch Biochem Biophys 438:93-102. https://doi.org/10.1016/j.abb.2005.03.020

Morrison RT, Boyd RN (1998) Química Orgánica, 5a . Edición, México, Ed. Addison Wesley Longman de México, S.A. de C.V.

Motorykin O, Santiago-Delgado L, Rohlman D, Schrlau JE, Harper B, Harris S, Harding A, Kile ML, Massey Simonich SL (2015) Metabolism and excretion rates of parent and hydroxy-PAHs in urine collected after consumption of traditionally smoked salmon for Native American volunteers. Sci Total Environ 514:170-177. https://doi.org/10.1016/j.scitotenv.2015.01.083

Nachev M, Schertzinger G, Sures B (2013) Comparison of the metal accumulation capacity between the acanthocephalan Pomphorhynchus laevis and larval nematodes of the genus Eustrongylides sp. infecting barbell (Barbus barbus). Parasite Vector 6:21. https://doi.org/10.1186/1756-3305-6-21

Nachev M, Jochmann MA, Walter F, Wolbert B, Schulte M, Schmidt TC, Sures B (2017) Understanding trophic interactions in host-parasite associations using stable isotopes of carbon and nitrogen. Parasite Vector 10:90. https://doi.org/10.1186/s13071-017-2030-y

Nachev M, Sures B (2016) Seasonal profile of metal accumulation in the acanthocephalan Pomphorhynchus laevis: a valuable tool to study infection dynamics and implications for metal monitoring. Parasite Vector 9:300. https://doi.org/10.1186/s13071-016-1576-4

Nelder JA, Wedderburn WM (1972) Generalized linear models. JR Stat Soc 135(3):370-384

Oluoch-Otiego J, Oyoo-Okoth E, Kiptoo KKG, Chemoiwa EJ, Ngugi CC, Simiyu G, Omutange ES, Ngure V, Opiyo MA (2016) PCBs in fish and their cestode parasites in Lake Victoria. Environ Monit Assess 188:483. https://doi.org/10.1007/s10661-016-5483-0
Palm HW (2011) Fish parasites as biological indicators in a changing world: can we monitor environmental impact and climate change? In: Mehlhorn H (ed) Progress in parasitology, parasitology research monographs, vol 2, pp 223-250. https://doi.org/10.1007/978-3-64221396-0 12

Pampanin DM, Kemppainen EK, Skoglanda K, Jørgensen K, Sydnesab $M$ (2016) Investigation of fixed wavelength fluorescence results for biliary metabolites of polycyclic aromatic hydrocarbons formed in Atlantic cod (Gadus morhua). Chemosphere 144:1372-1376. https://doi.org/10.1016/j.chemosphere.2015.10.013

Pascual S, Abollo E (2003) Acumulation of heavy metal in the whale worm Anisakis simplex s.l. (Nematoda: Anisakidae). J Mar Biol Assoc UK 83:905-906. https://doi.org/10.1017/ S0025315403008038h

Pemberton KD, Barrett J (1989) The detoxification of xenobiotic compounds by Onchocerca gutturosa (Nematoda: Filarioidea). Int $\mathrm{J}$ Parasitol 19:875-878. https://doi.org/10.1016/0020-7519(89) 90113-6

Pérez-del-Olmo A, Raga JA, Kostadinova A, Fernández M (2007) Parasite communities in Boops boops (L.) (Sparidae) after the prestige oil-spill: detectable alterations. Mar Pollut Bull 54:266-276. https://doi.org/10.1016/j.marpolbul.2006.10.003

Pérez-del-Olmo A, Montero FE, Raga JA, Fernández M, Kostadinova A (2009) Follow-up trends of parasite community alteration in a marine fish after the prestige oil-spill: shifting baselines? Environ Pollut 157:221-228. https://doi.org/10.1016/j.envpol.2008.07.010

Persson ME, Larsson P, Stenroth P (2007) Biomagnification and polychlorinated biphenyl congener distribution in an aquatic predator-prey, host-parasite system. Environ Toxicol Chem 26:837-843. https://doi.org/10.1897/06-305R.1

Precious WY, Barrett J (1989) The possible absence of cytochrome P-450 linked xenobiotic metabolism in helminths. Biochim Biophys Acta 992:215-222. https://doi.org/10.1016/0304-4165(89)90013-5

Ribeiro P, Diggle P (2016) geoR: a package for geostatistical analysis

R Core Team (2017) R: a language and environment for statistical computing. R Foundation for Statistical Computing. Vienna, Austria. http://www.R-project.org/. Accessed 15 January 2018

Sures B, Siddall R, Taraschewski H (1999) Parasites as accumulation indicators of heavy metal pollution. Parasitol Today 15:16-21. https://doi.org/10.1016/S0169-4758(98)01358-1

Sures B, Reimann N (2003) Analysis of tracemetals in the Antarctic hostparasite system Notothenia coriiceps and Aspersentis megarhynchus (Acanthocephala) caught at King George Island, South Shetland Islands. Polar Biol 26:680-686. https://doi.org/10.1007/s00300003-0538-4

Sures B, Siddall R (2001) Comparison between lead accumulation of Pomphorhynchus laevis (Palaeacanthocephala) in the intestine of chub (Leuciscus cephalus) and in the body cavity of goldfish (Carassius auratus auratus). Int J Parasitol 31:669-673. https:// doi.org/10.1016/S0020-7519(01)00173-4

Sures B, Siddall R (2003) Pomphorhynchus laevis (Palaeacanthocephala) in the intestine of chub (Leuciscus cephalus) as an indicator of metal pollution. Int J Parasitol 33:65-70. https://doi.org/10.1016/S00207519(02)00249-7

Sures B (2003) Accumulation of heavy metals by intestinal helminths in fish: an overview and perspective. Parasitology 126:53-60. https:// doi.org/10.1017/S003118200300372X

Sures B (2004) Environmental parasitology: relevancy of parasites in monitoring. Environmental pollution. Trends Parasitol 20:170 177. https://doi.org/10.1016/j.pt.2004.01.014

Sures B, Lutz I, Kloas W (2006) Effects of infection with Anguillicola crassus and simultaneous exposure with $\mathrm{Cd}$ and $3,3^{\prime}, 4,4^{\prime}, 5$ pentachlorobiphenyl (PCB 126) on the levels of cortisol and glucose in European eel (Anguilla anguilla). Parasitology 132:281-288. https://doi.org/10.1017/S0031182005009017 
Sures B, Nachev M, Selbach C, Marcogliese DJ (2017) Parasite responses to pollution: what we know and where we go in 'environmental parasitology'. Parasite Vector 10:65. https://doi.org/10.1186/ s13071-017-2001-3

Tairova ZM, Giessing AMB, Hansen R, Andersen O (2009) 1Hydroxypyrene as a biomarker of PAH exposure in the marine polychaete Nereis diversicolor. Mar Environ Res 67:38-46. https://doi.org/10.1016/j.marenvres.2008.10.005

Tenora F, Barus V, Kracmar S, Dvoracek J (2000) Concentrations of some heavy metal in Ligula intestinalis plerocercoids (Cestoda) and Philomera ovata (Nematoda) compared to some their host (Osteichthyes). Helminthology 37:15-18

Torres-Rivera A, Landa A (2008) Glutathione transferases from parasites: a biochemical view. Acta Trop 105:99-112. https://doi.org/10.1016/ j.actatropica.2007.08.005

Tsai IJ, Zarowiecki M, Holroyd N, Garciarrubio A, Sanchez-Flores A, Brooks KL, Tracey A, Bobes RJ, Fragoso G, Sciutto E, Aslett M, Beasley H, Bennett HM, Cai J, Camicia F, Clark R, Cucher M, De Silva N, Day TA, Deplazes P, Estrada K, Fernandez C, Holland PW, Hou J, Hu S, Huckvale T, Hung SS, Kamenetzky L, Keane JA, Kiss F, Koziol U, Lambert O, Liu K, Luo X, Luo Y, Macchiaroli N, Nichol S, Paps J, Parkinson J, Pouchkina-Stantcheva N, Riddiford N, Rosenzvit M, Salinas G, Wasmuth JD, Zamanian M, Zheng Y, The Taenia solium Genome Consortium, Cai X, Soberon X, Olson PD, Laclette JP, Brehm K, Berriman M (2013) The genomes of four tapeworm species reveal adaptations to parasitism. Nature 496:5763. https://doi.org/10.1038/nature12031

Vidal-Martínez VM, Centeno-Chalé OA, Torres-Irineo E, Sánchez-Ávila J, Gold-Bouchot G, Aguirre-Macedo ML (2014) The metazoan parasite communities of the shoal flounder (Syacium gunteri) as bioindicators of chemical contamination in the southern Gulf of Mexico. Parasite Vector 7:541. https://doi.org/10.1186/s13071014-0541-3

Vidal-Martínez VM, Torres-Irineo E, Romero D, Gold-Bouchot G, Martínez-Meyer E, Valdés-Lozano D, Aguirre-Macedo ML (2015) Environmental and anthropogenic factors affecting the probability of occurrence of Oncomegas wageneri (Cestoda: Trypanorhyncha) in the southern Gulf of Mexico. Parasite Vector 8:609. https://doi. org/10.1186/s13071-015-1222-6

Vidal-Martínez VM, Velázquez-Abunader I, Centeno-Chalé OA, MayTec AL, Soler-Jiménez LC, Pech D, Mariño-Tapia I, Enriquez C, Zapata-Pérez O, Herrera-Silveira J, Hernández-Mena DI, Herzka SZ, Ordoñez-López U, Aguirre-Macedo ML (2019) Metazoan parasite infracommunities of the dusky flounder (Syacium papillosum) as bioindicators of environmental conditions in the continental shelf of the Yucatan Peninsula, Mexico. Parasite Vector 12:277. https:// doi.org/10.1186/s13071-019-3524-6

Wang H, Li J, Zhang C, Guo B, Wei Q, Li L, Yang N, McManus DP, Gao X, Zhang W, Wen H (2018) Echinococcus granulosus sensu stricto: silencing of thioredoxin peroxidase impairs the differentiation of protoscoleces into metacestodes. Parasite 25:57. https://doi.org/10. 1051/parasite/2018055

Yadav M, Singh A, Rathaur S, Liebau E (2010) Structural modeling and simulation studies of Brugia malayi glutathione-S-transferase with compounds exhibiting antifilarial activity: implications in drug targeting and designing. J Mol Graphics Model 28:435-445. https://doi.org/10.1016/j.jmgm.2009.10.003

Yang Z, Shen Z, Gao F, Tang Z, Niu J (2009) Occurrence and possible sources of polychlorinated biphenyls in surface sediments. Chemosphere 74:1522-1530. https://doi.org/10.1016/j. chemosphere.2008.11.024

Zahra A, Pazooki J, Abtahi B, Reza-Shokri M (2013) Bioaccumulation of $\mathrm{Zn}$ and $\mathrm{Cu}$ in Chasar bathybius (Gobiidae) tissue and its nematode parasite Dichelyne minutus, southeast of the Caspian Sea, Iran. Indian J Geomarine Sci 42(2):196-200

Zar JH (1999) Biostatistical analysis, 4aed edn. Prentice-Hall, Inc., New Jersey, p 663

Publisher's note Springer Nature remains neutral with regard to jurisdictional claims in published maps and institutional affiliations. 